\title{
Public Transportation and Greenhouse Gas Emissions: A Case Study of the e Thekwini Municipality, South Africa
}

\author{
Alison Gopaul ${ }^{1}$, Elena Friedrich ${ }^{2 *}$ and Derek Stretch ${ }^{3}$ \\ ${ }^{1}$ School of Civil Engineering, Surveying and Construction, South Africa \\ ${ }^{2}$ University of KwaZulu-Natal, South Africa \\ ${ }^{3}$ Howard College Campus, South Africa
}

*Corresponding author: Elena Friedrich, University of KwaZulu-Natal, South Africa.

Received Date: May 10, 2019

Published Date: June 18, 2019

\begin{abstract}
Improving public transportation in the cities of the developing world is an opportunity to mitigate greenhouse gases (GHG). In South Africa the lack of formal and reliable public transport (PT) systems has prompted the proposal of integrated rapid public transport networks (IRPTNs) for implementation in 12 metropolitan municipalities and six districts, including the eThekwini Municipal Area (EMA). Motivated by the shortage of carbon emission studies and scenario analyses in the PT sector, this study serves as a benchmark for the GO!Durban system - the IRPTN planned for the eThekwini Municipality. A comparison of the baseline carbon emissions of the Business-As-Usual (BAU) Scenario and the ex-ante carbon emissions of the GO!Durban system in the year 2030, was carried out, according to several vehicle technology options. It was calculated that in 2030 the BAU scenario is predicted to emit between 380 to $482 \mathrm{kt} \mathrm{CO}_{2}$ equivalents $\left(\mathrm{CO}_{2} \mathrm{e}\right)$. The planned GO!Durban IRPTN system will lower these emissions to between 177 to $192 \mathrm{CO}$ e. These results showed that the implementation of the planned IRPTN will decrease greenhouse gas emissions of the PT sector of the eThekwini Municipality by $54 \%$ to $60 \%$ in 2030 . The procurement of efficient vehicle technology is the key factor in this development.
\end{abstract}

\section{Introduction}

Global transportation was identified as the source of 7 Gt carbon dioxide-equivalents $\left(\mathrm{CO}_{2} \mathrm{e}\right)$ of $\mathrm{GHG}$ emissions and responsible for $23 \%$ of total energy-related $\mathrm{CO}_{2}$ emissions in 2010. Without effective policy and enforcement, this is expected to increase to 12 Gt $\mathrm{CO}_{2}$ e per year by 2050 [1]. South Africa's transportation sector produced about 46.3 million tonnes of $\mathrm{CO}_{2}$ equivalents from consumption of petrol and diesel in 2008 [2]. The sector is responsible for $10 \%$ of the total GHG emissions in the country and emissions have increased by $32.2 \%$ between 2000 and 2010 [3,4]. It is estimated that SA produced $440 \mathrm{Mt} \mathrm{CO}_{2} \mathrm{e}$ in 2004 , a contribution of $1 \%$ to the global total in that year. Predictions according to 'growth without constraints' assumptions (no carbon constraints or energy efficiency plans) have estimated the 2050 South African emissions at $1600 \mathrm{Mt} \mathrm{CO}_{2} \mathrm{e}$, almost quadruple those of 2004 [5]. In the eThekwini Municipality annual emissions from passenger cars alone have been estimated at 2.14 $\mathrm{MtCO}_{2} \mathrm{e}$ [6] and for Johannesburg this estimate is about $4.13 \mathrm{MtCO}_{2} \mathrm{e}$ [7] Therefore, transportation is a major source of GHG emissions at global, national and local level and one way of reducing these emissions is the implementation of functional and efficient public transport systems $[8,9]$. It is thought that "good opportunities exist for both structural and technological change around low-carbon transport systems in most countries but particularly in fast growing emerging economies where investments in mass transit and other low-carbon transport infrastructure can help avoid future lock in to carbon intensive modes" [1]. Therefore, it is important to consider these opportunities when developing South Africa's new IRPTNs and this process can provide lessons that can help other cities in developing countries. The limited investment in the South African public transport sector over the past 30 years has prompted urgency for improvement. It is considered that "public transport in South Africa is one of the most burning issues in the transport sector" [10] and a detailed review of the policy developments and their implementation was conducted $[10,11]$. The existing public transportation system in most cities in 
the country comprises limited bus and rail lines, and the informal sector with operation of unreliable road vehicles [12] known as "minibus taxis", which are transporting an estimated $65 \%$ of all commuters in the country [10]. Minibus taxis, in South Africa, are usually 15-20 seat privately owned vehicles with fixed routes but no fixed time schedules. This situation has historical roots. The legacy of the apartheid era has greatly influenced PT in SA and is still being addressed today. The implementation of apartheid policies (1948-1994), which introduced racial segregation, created long commuting distances between areas assigned to different racial groups, which were separated by urban apartheid planners by "buffer zones" (mostly large undeveloped areas). Low quality and low coverage services by the formal public transport system, particularly in the disadvantaged townships, encouraged the operation of minibus-taxi services and although unsafe and unsustainable, commuters had turned to this mode for mobility. After the introduction of minibuses, in the 1970s and 1980s, the South African Black Taxi Association and Transport Deregulation Act of 1988, attempted to control this unregulated industry and permits were issued. The number of permits increased by $2537 \%$ over the next five years to 38317 and reached 50000 minibuses nationally in the early 1990s [13].

After the fall of apartheid, privatisation and profit-oriented public transportation services have emerged. However, these were associated with low levels of service, unstable government subsidies and reduced ridership, but the impact on fuel usage and emissions was not a major concern in the sector. In recent years inadequate capital for upgrades, lack of structure, control and enforcement, poor driving practices, duplicate and illegal services [10], lack of service and fare integration, and safety [14] are but a few of the major obstacles faced by the existing public transportation system (made up of the formal and the informal sectors). This has exacerbated privately-owned vehicle (POV) purchase and usage, further reducing PT ridership [12]. In an effort to combat the increasing issue of congestion in many municipalities, right of way (ROW) bus lanes have been implemented along major freeways, along with additional lanes and flyovers. The additional road reserve creates a greater lane capacity to accommodate more vehicles but does not alleviate the issue of congestion [6]. The South African Department of Transport (DoT) introduced the Public Transport Action Plan (PTAP) in 2007 to put the Public Transportation Strategy into practice. It focuses on two key areas: accelerated modal upgrades and IRPTNs in up to 12 cities and 6 districts in South Africa over a 20-year period [4]. It also has to be noted that the taxi recapitalization programme (TRP), targeting minibus taxis, was introduced by the government in 2006. It involves the scrapping of old minibus-taxis for an allowance and the voluntary replacement with new vehicles (which are approved by the South African Bureau of Standards). It is important that sustainable practices are adopted for the transformation of the sector with attention to the planning and implementation processes as public transport can create the opportunity for GHG mitigation [6] and large-scale infrastructure development must be of benefit to both the public and the environment. This study aims to quantify the operational carbon footprint (CF) of the proposed local IRPTN (GO!Durban), and assess its ability to reduce GHG emissions in comparison with the existing PT system. The eThekwini Municipality is located within the Province of KwaZulu-Natal on the eastern coast. The municipality has a population of about 3.5 mil people and covers an area of $2297 \mathrm{~km} 2$, with a coastline of $98 \mathrm{~km}$ along the Indian Ocean [15]. The core city of this municipality is Durban, which has the largest port in the country and the subcontinent. Inland, Durban is surrounded by other urban nodes, as well as other more sparsely populated peri-urban areas. Currently, about $40 \%$ of the population uses public transport, mostly taxis (68\%), buses (25\%) and rail (7\%) [15]. Approximately 1600 unidirectional bus routes, which are serviced by approximately 200 operators (in a mix of subsidised contracts and unsubsidized services), exist in the city. There are also approximately 1500 unidirectional taxi routes, serviced by 120 taxi associations in the municipal area [15]. However, overall the public transport system is considered economically inefficient with many services in direct competition with each other, resulting in unprofitable rail and bus trips [16]. In effort to provide a safe and accessible PT network, the evolutionary GO!Durban system will replace the existing formal and informal public transport available in the municipality. The nine planned corridors comprise eight BRT trunk routes and a rail trunk corridor, serviced by feeder routes and assisted by a complementary quality bus service. The trunk routes will total $250 \mathrm{~km}$ in length, including $60 \mathrm{~km}$ of rail network. The full network will be within an $800 \mathrm{~m}$ (10-15 minute) walking distance for more than $85 \%$ of the eThekwini region [15]. Figure 1 presents the planned system in the context of the eThekwini Municipality and the country (Figure 1).

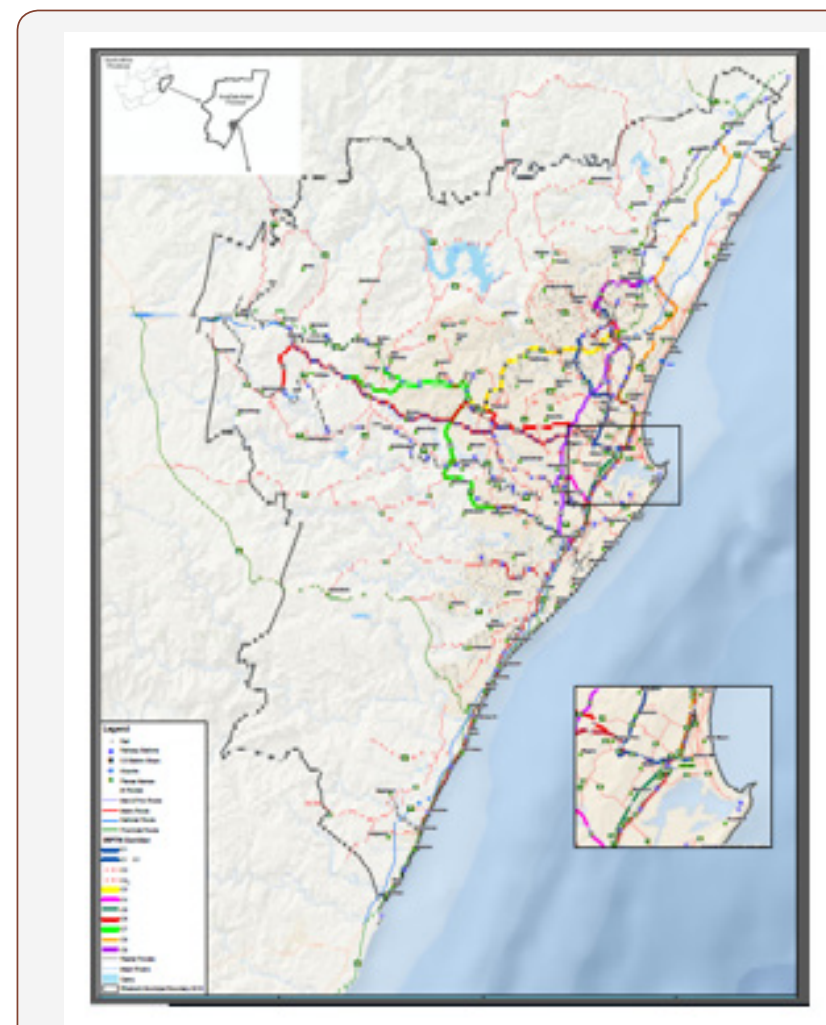

Figure 1: The IRPTN planned for the eThekwini Municipality. 
GHG Reductions and Pt Experiences in the Developing World-A Brief Literature Review

The published body of literature agree that $\mathrm{CO}_{2}$ emissions due to transportation can be lowered in a city in a developing country, through the implementation of a variety of interventions like reducing transport demand, reducing car use, improving alternative transport modes, improving road network and improving vehicle technologies $([17,18]$. All these interventions are linked with public transportation in one way or another. Crozet \& Lopez-Ruiz [19] argued that the immediate introduction of new technology for public transport is the most effective way to reduce emissions from transportation. Thereafter, human choices and behaviour towards available options must be addressed. Zahabi et al. [8] indicate that reduction of GHG emissions can best be achieved by increasing the accessibility of PT services. The implementation of reliable PT services may decrease the dependence on POVs. In addition, disincentives for POV usage include: enforcing car-free zones, restricting POV usage on specific days of the week (similar to Bogota), more stringent POV monitoring (vehicle licenses and roadworthiness) and penalties, implementing or increasing taxes, fuel levies, parking fees and road user charges on POVs [9]. Other studies showed that increasing the ridership of PT services through policy focused on PT priority will have the most success with regard to reducing GHG emissions [9]. As well as improving service quality of PT facilities, high ridership and possible modal shifts towards PT can be achieved by the following measures: improved nonmotorised transport (NMT) walking and bicycle facilities, provision of park and ride facilities [20], promotion of PT as cheaper and less harmful to the environment, and address of negative public perception to PT [18].

Urban planning also plays an important role in reducing GHG emissions in the transport sector by creating densely populated areas with proper access to PT 18]. International studies have shown that, in countries with population and travel patterns similar to South Africa, BRT systems present the greatest success in transforming and reducing GHG emissions in the transport sector [21]. According to Mejia-Dugand et al. [22] "BRT does not represent transformation as such, but a means to achieve transformation". Transformation of existing PT systems can be achieved by a leapfrog or incremental approach [12] In terms of transport planning, in order to establish a high-quality PT system, leapfrogging implements one corridor at a time at a single geographic location. The outcome of this approach will only be seen at the end of the project or phase and might be irreversible or too expensive to correct. In addition, cities not immediately targeted may experience a long waiting period before improvement. In contrast, the incremental approach simultaneously addresses one issue across all areas, such as formalizing the minibus-taxi industry in South Africa, thereby improving all systems in the same way and retaining patronage [12]. In terms of GHG emissions both these approaches will have different outputs, which will influence these emissions during the construction and roll-out of a PT system. However, once the system is in place the resultant GHG emissions will stabilize. Nair P \& Kumar D [18] also showed that GHG emissions from urban transport, including public transportation, depend on the development stages of a city and that mass-transit systems (such as the IRPTNs) are the starting point. However, as the city develops, they are insufficient and need to be complemented by other interventions (i.e. emission standards, traffic control and road pricing).

\section{South African IRPTNs and Local GHG Emission Studies}

In 2015 operational IRPTNs in South Africa included Rea Vaya BRT System - City of Johannesburg, MyCiTi - Cape Town Integrated Rapid Transit, and Libhongolethu Integrated PT System - Nelson Mandela Bay Municipality. Other systems like Rustenburg Rapid Transit - North West Province, A Re Yeng - City of Tshwane BRT, Msunduzi IRPTN, and GO! Durban are in the planning and early implementation phases. Although the IRPTN systems have strong support from all levels of government, there have been challenges in the implementation. These challenges influence the efficiency of the public transport system and the associated GHG emissions calculated. Inadequate planning and communication are seen as the main issues faced in the implementation of IRPTNs in South Africa. Participation is essential to the development process and communication between providers and those affected must be effective and result in an acceptable outcome [13]. Other challenges are historical, for example, attempts to formalise the minibus-taxi industry, for integration of services, were faced with resistance across all networks [10]. Another example of a challenge faced was in the Nelson Mandela Bay Municipality (core city being Port Elizabeth), where a BRT system similar to that established in Pereira (Columbia) was selected and implemented onto the existing road network. The ROW lane had to go through the city centre which resulted in narrow lanes that did not provide adequate turning space and on-street parking, reduced pedestrian and loading zones and negative impacts on business. Therefore, the network was a failure and required further investment for correction [13]. In the South African literature, there are only 2 studies [23,24] quantifying GHG emissions from public transportation systems. These two studies investigate the City of Johannesburg and surrounding areas. Therefore, there is an absence of GHG emission studies in most large municipalities in the country, although carbon studies should serve as an indicator of environmental impact and project viability for informed decision-making. This research serves as an attempt to fill the gap with regard to the case study of the eThekwini Municipality.

\section{Methodology}

This study evaluates the operational GHG emissions of the PT fleet within the eThekwini Municipality, defined as the total $\mathrm{CO}_{2} \mathrm{e}$ emissions produced during a reference year. An assessment of vehicular emissions for the business as usual (BAU) scenario of the current PT system as projected from 2015 to 2030 was conducted and compared to the projections of the GO!Durban system for the same years. The year 2030 was chosen as the final comparison year since the GO!Durban system is predicted to be finalized by 2027. A model was developed to calculate the emissions of the existing PT system and the GO!Durban system with primary travel data 
extracted from a traveling demand model developed for the city (INRO EMME/2). This program was calibrated for macroscopic studies within the eThekwini Municipality and is based on a fourstep model (trip generation, distribution, assignment and modal choice). The origin-destination data in the forecasting model was built based on the 2008 household travel survey and 60 areas and 338 zones have been delimited for the municipality. It includes expected populations growth and spatial developments, as well as vehicle origin-destination data (routes and frequencies) and expected passages boarding. A series of assumptions, as well as relevant emission factors and fuel (energy) consumption estimates, were applied and GHG emission figures were calculated for the defined scenarios. These results were used to evaluate the ability of GO!Durban to reduce emissions as compared to the current PT system, whilst providing formal public transportation. There are many approaches and key variables, suggested in the literature, for the calculation of GHG from public transportation. Bubeck et al. [24] give a good summary of these in the South African context. The current study followed a similar approach to those employed by Bubeck et al. [24] and Gütter [23], however, the scope of the model developed was larger as it included the entire IRPTN developed for the eThekwini Municipality and not only parts of a municipal area as done by the above-mentioned authors with regard to the City of Johannesburg and parts of the Gauteng Province.

\section{Business-As-Usual (BAU) Scenario}

Comprehensive analyses of the current system (consisting of the entire functional fleet; both railway and on-road transportation) according to a BAU scenario involved projections from the 2008 Household Travel Survey to 2030. The BAU scenario implies growth without constraints. This scenario considered projections of the existing PT system and was carried out with the assumption that no major PT interventions were implemented (other than fleet renewal and maintenance). Three cases considering technological improvements were investigated under the BAU Scenario, namely: Option 1 - refurbishment of existing fleet (no improvements), Option 2 - annual technology improvement (factors applied), and Option 3 - introduction of latest vehicle technology available.

\section{GO! Durban Scenario}

As stipulated by the Public Transport Action Plan, a passenger modal shift of $20 \%$ towards PT is generated by the GO!Durban Scenario. The preliminary plans and latest available information on GO!Durban, were used for this study. The following vehicle technology options have been assumed for each emission projection of GO!Durban: Option 1 - Same vehicle technology

used for all phases of GO!Durban, Option 2 - Annual technology improvements (factor applied) from 2015, and Option 3 - Latest available vehicle technology introduced across all corridors in 2030. Due to limitations on scenario modeling, only the fully operational network (planned to be implemented by 2027) is considered in the 2030 forecast.

\section{Use of the Transportation Forecasting Software for Data Extraction}

In the literature there are a variety of methodologies and models to forecast and evaluate public transport systems. The Emme/2 model [17] is used by the eThekwini Transport Authority (ETA) to aid in transportation planning. A travel demand model exists for the city and is based on the 2008 origin-destination data from the Household Travel Survey. The Emme/2 morning peak hour scenario outputs include: 2008 travel data and, projections for 2015, 2020, 2025 and 2030. The outputs from this model were used to calculate passage kilometers, passage hours, vehicle trips and mileage of each type of vehicle mode. Conversion of the morning peak hour (5:00 to 8:00 am) outputs to annual traffic data was done in accordance with modal split proportions obtained from results of the Household Travel Survey of 2008. The low-population growth forecasts extracted from EMME/2 for the existing PT modal split represents the BAU scenario. It assumes that the modal share of PT (44\%) remains unchanged. The frequency of trips modelled for the GO!Durban scenario was designed for a constant vehicle headway along routes. Although the usage of non-motorized transport (NMT) has not been measured, the increase in NMT facilities as a component of GO!Durban promotes walking and cycling and will further increase their share of NMT contribution.

\section{Data Analysis}

The "Carbon Development Mechanism (CDM) AM0031 Largescale Methodology: Bus rapid transit projects Version 05.0.0" and "Tool to calculate baseline project and or leakage emissions from electricity consumption" assisted in the calculation of projected $\mathrm{CO}_{2}$ e emissions. Table 1 details the assumptions applied to each technology option of the BAU Scenario, including European (Euro) emission standards. Buses and minibus-taxis were replaced at the end of useful life in Option 1. Option 2 investigated the projection of vehicle emissions with the application of a $99 \%$ annual technology improvement factor [2] to the existing bus and minibus-taxi fleet. Option 3 introduced the X'Trapolis Mega steadily over 10 years, replacing the existing PRASA (Passenger Rail Agency of South Africa) rolling stock (Table 1).

Table 1: Assumptions for each option of the BAU scenario.

\begin{tabular}{|c|c|c|c|}
\hline \multirow{2}{*}{$\begin{array}{c}\text { Vehicle } \\
\text { Category }\end{array}$} & No Technology Improvements & Option 2 & Annual Technology Improvement \\
\cline { 2 - 4 } Passenger Rail & Refurbishment of existing rolling stock & 0.68 kg CO2/kWh in 2030 (Eskom Holdings, 2011) & $\begin{array}{c}\text { X'Trapolis Mega Trains } \\
\text { (replacement from 2017 to 2027) }\end{array}$ \\
\hline Bus & $\begin{array}{c}\text { Replacement of vehicles by Scania 4x2 } \\
\text { (Euro III) }\end{array}$ & $\begin{array}{c}\text { Application of the AM0031 0.99 annual } \\
\text { technology improvement factor (CDM, 2011) }\end{array}$ & $\begin{array}{c}\text { Replacement of vehicles by Volvo } \\
\text { B7R (Euro V) }\end{array}$ \\
\hline Minibus-Taxi & $\begin{array}{c}\text { Replacement of vehicles by Toyota } \\
\text { Quantum/Ses'Fikile (Euro II) }\end{array}$ & $\begin{array}{c}\text { Replacement of vehicles by } \\
\text { Mercedes Benz Sprinter (Euro V) }\end{array}$ \\
\hline
\end{tabular}


Vehicle replacement would be instantaneous, creating a staggered trend, with the useful life of 10 years for minibus-taxis and 12 years for buses [25].

\section{$\mathrm{CO}_{2} \mathrm{e}$ Emissions for the GO! Durban scenario}

The wall-to-wall GO!Durban network was modelled according to the 2030 projection. The case study evaluates the total emissions of the entire network for the year of 2030, comprising $\mathrm{CO}_{2} \mathrm{e}$ emissions from the following vehicles:

- $\quad$ X'Trapolis Mega Trains - Passenger Rail Corridor;

- $\quad$ Articulated Bus - Eight BRT Trunk Routes;

- $\quad$ Standard Bus - Feeder and Complementary Routes;

- $\quad$ Midibuses (minibuses larger than traditional ones with approximately 28 seats) and

- $\quad$ Minibus - Feeder and Complementary (Comp) Routes.

On-road vehicles for GO!Durban are yet to be selected; however, a Euro Emission Standard IV requirement has been specified [26]. Therefore, vehicles used by existing BRTs (Rea Vaya and MyCiTi) in South Africa have been selected as possible choices for the purpose of this study. The X'Trapolis Mega Train is the new rolling stock to be manufactured specifically for the rail corridor of GO!Durban [7] and emission data was collected from the manufacturers.

\section{Limitations and Uncertainties}

Several factors give rise to limitations and uncertainties in this study. In particular, incomplete and/or inadequate data due to their limited availability or confidentiality issues, and time constraints are some of the limitations encountered. Other factors are due to the EMME/2 model assumptions, bus fleet assumptions and the progress of the taxi recapitalization programme (TRP). In addition, a conservative approach was adopted in the selection of the vehicles for feeder and complementary routes. A series of sensitivity analyses undertaken showed that these three factors did not play an important role and the results were robust with regard to these inputs. The primary source of data was EMME/2 traffic forecasting software used by the ETA to assist in transportation planning. The 2008 base-year model lacks some of the more recently planned spatial developments and, therefore, creates gaps in modeling. Hence, some uncertainty was introduced due to changes in PT and spatial development post 2008, including the development of the northern urban development corridor (NUDC), consequent trips generated and the influence on traffic. In addition, concurrent modeling of scenarios is not possible, therefore, the development of the GO!Durban system through a 'phasing' scenario could not be tracked, limiting modeling of future events. The availability of detailed data in the context of cities in developing countries, and in particular in South Africa, proves to be the most important limitation for future modeling and calculations, not only for transportation but also for other areas.

\section{Result and Discussion}

The annual $\mathrm{CO}_{2}$ e emission results from the investigation of the PT system within the eThekwini Municipality are presented for the
BAU Scenario, GO!Durban Scenario and a comparison of BAU and GO!Durban Scenario is made.

\section{BAU scenario}

The forecasted operational $\mathrm{CO}_{2} \mathrm{e}$ emissions of the "growth without constraints" scenario are presented in Figure 2, according to three vehicle technology options(Figure 2).

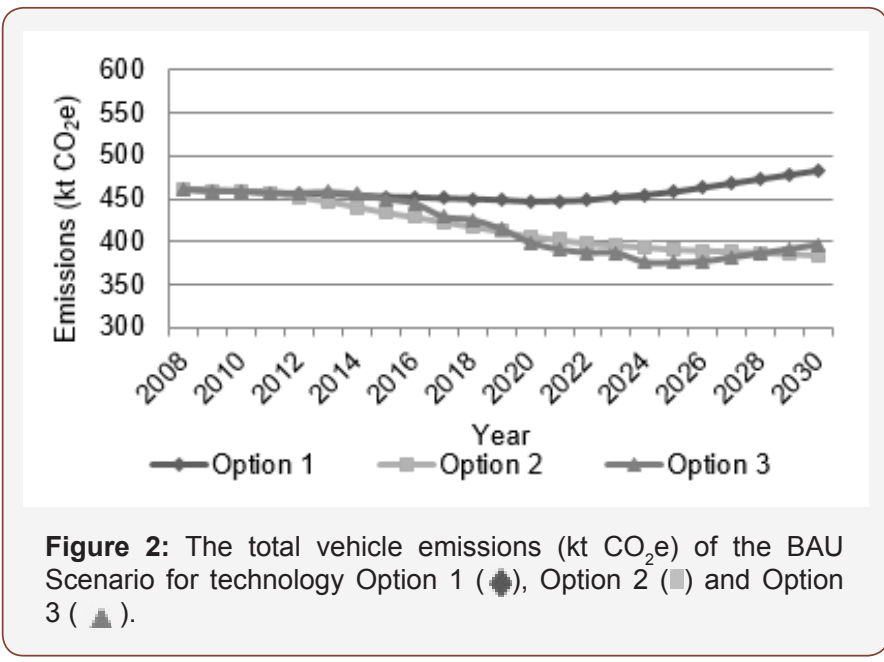

Figure 2 presents all emission profiles for the BAU scenario projected from $461 \mathrm{kt} \mathrm{CO}_{2} \mathrm{e}$ in 2008. In 2030, Option 1 produces the greatest emissions at $482 \mathrm{kt} \mathrm{CO}_{2} \mathrm{e}$, displaying an overall $5 \%$ increase from 2008. Option 2 indicates a steady decline with the greatest decrease in emissions to $384 \mathrm{kt} \mathrm{CO}_{2} \mathrm{e}$ in 2030 and is due to annual improvements in fleet technology and fuel advancements to accommodate undetermined vehicle upgrades. Option 3 displays distributed drops to $397 \mathrm{kt} \mathrm{CO}_{2} \mathrm{e}$ in 2030 , according to required fleet replacements. Option 2 and 3 display decreasing trends of GHG emissions in 2030,17\% and $14 \%$ less than 2008, respectively. This indicates the importance of new fleet developments and the impact of selection.

In Option 1, passenger rail, comprising approximately $46 \%$ of annual emissions, is expected to be a more efficient vehicle mode than buses. The ageing fleet procured in 1958 [27] has undergone refurbishment, but has never been replaced due to a shortage of funds and, therefore, cannot ensure lower emissions. Although distances travelled by minibus-taxis increase the most $32 \%$ from 2008 to 2030), the introduction of new vehicles by the TRP reduces emissions to below $80 \mathrm{kt} \mathrm{CO}_{2} \mathrm{e}$. The overall consistency of total emissions is primarily due to the considerable impact of the TRP. These results underline the importance and potential of the TRP as a local strategy which also reduces GHGs. Especially smaller South African cities, that will not typically have any other interventions in terms of PT, would benefit in a similar way. In Option 2, Eskom's (the national energy entity) attempts to improve the carbon footprint of electricity generation even with growing demand up to 2030 [28], have significantly reduced the emission forecasts for Metrorail. Eskom is the state-owned monopoly electricity generation company in South Africa and, due to the fact that about $86 \%$ of the electricity is generated from coal, the resultant GHG emissions are high (about $1.015 \mathrm{~kg} \mathrm{CO}_{2}$ e per $\mathrm{KWh}$ produced and 
distributed in South Africa) [28]. When modelling this PT option, a $29 \%$ decrease in emissions (from 2008 to 2030) is evident, the most substantial among the PT vehicles. Although passenger rail produces the most GHG emissions over the projection, the bus service emissions exceed those of the rail fleet in 2030, due to passenger capacity and more efficient electricity generation for rail use. Option 3 demonstrates a decreasing trend to 2025 (375 $278 \mathrm{t} \mathrm{CO}_{2} \mathrm{e}$ ) during the replacement of the PRASA rolling stock with the $\mathrm{X}^{\prime}$ Trapolis Mega. After the switch to newer, safer and more energy efficient vehicles, the emissions of the minibus-taxi industry increase according to rising passenger usage. The percentage of minibus-taxi emissions is equal to that of passenger rail emissions. Although minibus-taxis provide an essential service as feeders and connectors between railway stations and destinations, passenger rail services are competitive with the additional advantage of travel along railway tracks without road traffic. The $42 \%$ decrease in passenger rail emissions is predominantly due to the introduction of the X'Trapolis Mega, coupled with the sustainability plans of Eskom, highlighting the impact of passenger rail rolling stock.

In 2030, Option 1 produces the most and Option 2, the least annual expected emissions in the BAU scenario. When considering the average emissions for each option, Option 2 and 3 are the most effective with $418 \mathrm{kt} \mathrm{CO}_{2} \mathrm{e}$ annually, followed by Option 1 (458 kt $\mathrm{CO}_{2} \mathrm{e}$ ). In terms of sustainability, although vehicle advancement has not been specified, Option 2 produces the solution with least environmental impact. It is apparent that, while Option 3 is dependent on the rate at which new rolling stock is introduced with defined optimum technology advancements, it is the more accurate alternative for the BAU scenario. Examining the consequence of modal assignment, the contribution of each mode to the overall 2030 emissions for all options are summarized in Figure 3 (Figure 3).

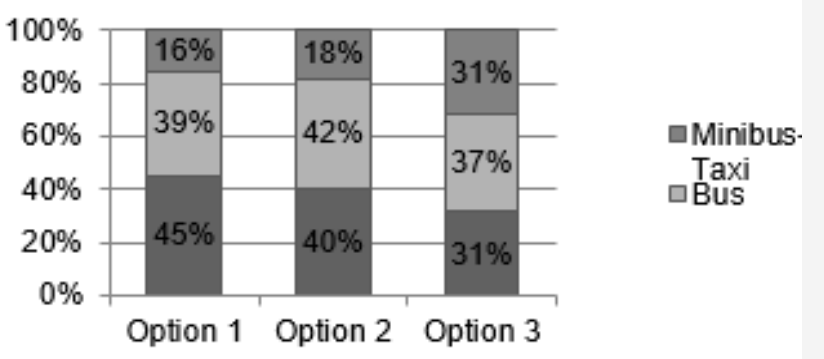

Figure 3: Emission split per minibus-taxi, bus and passenger rail vehicle category for all options of the BAU scenario in 2030.

In 2030, Option 1 and 2 display similar emission compositions, however, a slight decrease in passenger rail emissions is observed in Option 2 with the application of Eskom mitigation. The overall adjustment in the shares of emissions for Option 3 is due to the introduction of new rail rolling stock and Euro V vehicle technology, which has produced a decrease in the proportion of bus and passenger rail emissions. In 2030 despite the vehicle technology assigned, GHG emissions from the bus fleet exceed other releases. Although the greatest distance is driven by minibus-taxis (owing to the reduced passenger capacity), this mode still produces the least emissions over Option 1 and 2. The apparent increase in the minibus-taxi segment of Option 3 is due to the introduction of a more advanced vehicle and the considerable decrease in passenger rail proportions. The proportion of bus emissions is comparable for all options. Although the distance driven by buses is only $27 \%$ of minibus-taxis, this does not reflect in the share of emissions produced as bus emissions are more than double those of minibustaxis in Option 1 and 2. Minibus-taxis are the most efficient mode, transporting $57 \%$ of the annual passenger demand and releasing only $16 \%, 18 \%$ and $31 \%$ of total emissions over all options. In Option 3, however, emissions produced by rail and minibus-taxis are equal, displaying the success of the X'trapolis Mega in reducing emissions. During the peak periods, the high passenger demand of the rail service in one direction, results in low occupancy trains (with the same capacity) on the return trip. While this seems unproductive, the passenger rail system is still the most efficient means of transporting high volumes during peak hours. Minibus-taxi services, although unscheduled, are more profitable considering that trips are only made when the vehicles are full.

\section{GO!Durban scenario}

This section presents the expected vehicle emissions of the GO!Durban network to be implemented in the eThekwini Municipality. The anticipated timeframes specified indicate that the entire network will be online and functional in 2027 [16]. Due to data modeling constraints, for the purpose of this study, 2030 was considered as the operational date of the entire system. The GO!Durban $\mathrm{CO}_{2} \mathrm{e}$ emissions produced for the three technology options are presented. Vehicles similar to those operating in Rea Vaya (BRT of Johannesburg) and MyCiTi (BRT of Cape Town) were selected for use by GO!Durban. It is possible, however, that smaller buses would adequately meet the demands along the complementary bus routes in the initial stages with lower ridership. Once fully implemented, however, larger buses may be introduced for greater capacity, as considered in this scenario. The total emissions produced by the vehicles selected for GO!Durban start as the first corridor comes online in 2016 [16]. Emissions of the network increase with the addition of corridors until the wall-to-wall system is achieved in 2027. Thereafter, the entire network is expected to stabilise and continue operation to the year 2030, The estimated 2030 GHG emissions produced by the functional GO!Durban system providing PT services in the EMA are summarized in Figure 4 (Figure 4).

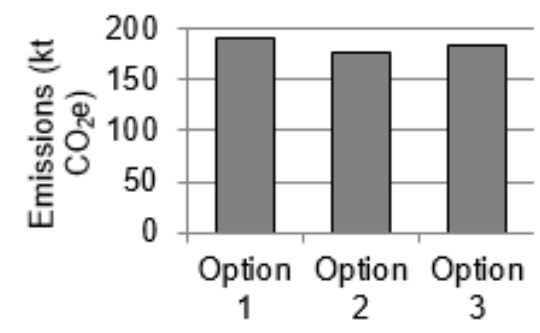

Figure 4: 2030 Emissions comparison for all options of the GO!Durban scenario. 
The final 2030 emissions for Option 1, 2 and 3 are: $192 \mathrm{kt} \mathrm{CO}_{2} \mathrm{e}$, $177 \mathrm{kt} \mathrm{CO}_{2} \mathrm{e}$ and $183 \mathrm{kt} \mathrm{CO}$ e, respectively. Option 2 and 3 are $7 \%$ and $5 \%$ lower than Option 1, respectively. These reduced emissions indicate the impact of technology advancement, which appears minor in 2030, however, the effect of which is considerable over several years of operation. Option 2 which accounts for unknown vehicle upgrades, appears to be the most sustainable alternative. Option 3, although producing greater GHG emissions, realistically considers technology improvements according to actual available choices. Although further developments are inevitable in the next 15 years, it is unlikely that the latest (Euro V) technology will be procured, as existing national Euro Emission Standards in SA are Euro II regulations (Delphi, 2014/2015). Although Option 1 produces the greatest emissions, the probability of the trunk articulate buses and standard buses being similar to those chosen for this study is favourable. A detailed summary of the modal emission proportions for each option of the GO!Durban Scenario is provided in Table 2 (Table 2).

Table 2: Emissions per vehicle category for the GO!Durban scenario for the year 2030 .

\begin{tabular}{|c|c|c|c|c|}
\hline \multirow{2}{*}{ Route } & Mode & Option 1 & Option 2 & Option 3 \\
\hline \multirow{2}{*}{ Trunk } & $\begin{array}{c}\text { Passenger } \\
\text { Rail }\end{array}$ & $47 \%$ & $50 \%$ & $49 \%$ \\
\cline { 2 - 5 } & $\begin{array}{c}\text { Articulated } \\
\text { Bus }\end{array}$ & $18 \%$ & $17 \%$ & $19 \%$ \\
\hline \multirow{2}{*}{ Feeder } & Bus & $8 \%$ & $7 \%$ & $6 \%$ \\
\cline { 2 - 5 } & Midibus & $2 \%$ & $2 \%$ & $4 \%$ \\
\hline \multirow{2}{*}{ Complementary } & Bus & $24 \%$ & $22 \%$ & $19 \%$ \\
\cline { 2 - 5 } & Midibus & $2 \%$ & $2 \%$ & $3 \%$ \\
\hline
\end{tabular}

The vehicle GHG emission proportions of all options are almost identical. The midibus proportions of Option 3 are slightly higher, due to the selection of a larger capacity vehicle adhering to higher emission standards. This has reflected as lower feeder and complementary bus emission shares. The effect of technology upgrade is apparent in Option 2 and 3 of complementary bus emissions, which are $2 \%$ and $5 \%$ less than Option 1 , respectively. As displayed in Figure 4, the highest emissions are produced by the rail corridor, a trunk route for provision of services to $40 \%$ of eThekwini's Municipality PT demand [16]. Therefore, the anticipated result of $47 \%-50 \%$ of total emissions is acceptable bearing in mind the safety of travel by rail, as well as convenience and advantage of ROW. The remaining 53\% of emissions result from the operation of road vehicles. Complementary buses produce the greatest bus emissions, followed by BRT trunk buses and feeder buses, in proportion with the respective distances driven along the routes. Emissions from midibuses comprise less than $2 \%$ of 2030 totals each, an efficient result for their combined $36 \%$ of total road trip distances. Overall trunk routes produce the greatest emissions (65\% - 68\%), followed by complementary routes $(22 \%-26 \%)$ and feeders $(9 \%-10 \%)$. There is a noticeable variance of the rail trunk and complementary bus routes, with emission proportions of the latter being higher for Option 1 and 2. Trunk routes transport a significant number of passengers along concentrated corridors, however, complementary routes consist of numerous shorter routes with reduced patronage which may require smaller vehicles. This scenario considers the worst case of articulated (large) buses for trunk routes and standard (medium-sized) buses for complementary and feeder routes, resulting in the maximum emissions for GO!Durban. Reducing emissions along complementary routes would require customizing each route according to passenger demand, with larger buses for major demand and midibuses for small demand. Adjustment to preliminary plans, however, can only be made once the system has been implemented and gaps established.

The results indicate that travel by road transportation produces less GHG emissions in comparison to trains. There is a sizable difference between the eight BRT trunk routes and the single rail corridor of $29 \%-33 \%$ across all options, indicating that articulate buses are environmentally better. The required road reserve of the designated bus lanes, in addition to escalating mixed traffic on other lanes, however, contribute to the feasibility of faster, safer and more convenient travel by passenger rail.

\section{Comparison of BAU and GO!Durban scenarios}

The contrast in total emissions resulting from the existing PT system and the IRPTN to be implemented is presented in this section, with consideration of vehicle assignment to individual routes for all options. The emissions produced by the BAU scenario are shown from 2008 and although the operation of the implemented corridors of GO!Durban begins in 2016 [16], due to modeling constraints, potential emission reductions could not be measured from this point and instead comparison of the entire network in 2030 was conducted. The projected emissions for both the BAU scenario and GO!Durban vary depending on the availability and selection of vehicle technology. GO!Durban creates an opportunity to reduce the emissions of the PT system within the EMA, for which the total 2030 estimations (with both scenarios operating as individual entities) are comparable. Potential emission alleviation for each option is shown in Figure 5 (Figure 5).

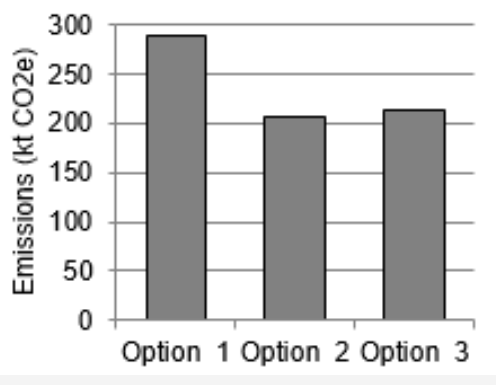

Figure 5: 2030 Estimated emission reductions achievable by GO!Durban for all vehicle options.

The emission differences between the BAU scenario and GO!Durban, as displayed in Figure 5 for the year 2030, range from $207 \mathrm{kt} \mathrm{CO}_{2} \mathrm{e}$ to $290 \mathrm{kt} \mathrm{CO}_{2} \mathrm{e}$. These significant emission improvements brought about by the launch of GO!Durban would diminish the GHG emission of the PT sector of the eThekwini 
Municipality by $54 \%$ to $60 \%$. This would reduce the local GHG emissions of the transportation sector on the whole. Therefore, all IRPTN advancements and associated GHG mitigation would be extensive on a municipal and national level. In 2030, the projected emissions of the national transport sector is approximately 150 $000 \mathrm{kt} \mathrm{CO}_{2} \mathrm{e}$ under the 'growth without constraints' scenario [5]. A reduction of GHG emissions of $290 \mathrm{kt} \mathrm{CO}_{2} \mathrm{e}$ in 2030, resulting from the implementation of GO!Durban, implies a $0.19 \%$ decrease in the total emissions of the transport sector in SA. This may seem minor, however, in addition with the other IRPTNS and mitigation strategies in PT and the transport sector on the whole, it has the potential to have a significant impact on GHG emissions and the environmental impact of transportation in SA. The major GHG contributor in the BAU scenario is the outdated railway rolling stock used by PRASA, which if upgraded alone would reduce emissions significantly. Option 1 indicates the highest reduction in emissions, due to the presence of formal and informal operations of the BAU Scenario, however, the possibility of technology advancement in the BAU Scenario has not been explored in this option. For Option 1, owing to the outdated PRASA rolling stock and unsustainable electricity generation, the greatest emission reductions are measured along passenger rail routes. Option 2 displays a smaller, still significant, drop in passenger rail emissions due to the consideration of the electricity GHG emission reduction objectives in the BAU Scenario. In Option 3, the assignment of the $\mathrm{X}$ 'Trapolis Mega to both scenarios results in a smaller decrease in rail emissions and the introduction of latest bus technology has decreased emissions in the BAU Scenario. For Option 3, vehicles being manufactured for MyCiTi were selected for the GO!Durban Scenario and, although it is unlikely that Euro V Standard vehicles will be procured for the starting phases of GO!Durban (considering SA's current Euro II Emission Standard regulations), it serves as an accurate estimate for 2030. Although midibuses require a greater road reserve due to reduced passenger capacity, it has been shown that this vehicle category produces the least emissions over all projections. The sustainability goals of Eskom to be achieved in electricity generation have been included in this study, however, it is unclear whether Eskom will meet their targets to reduce $\mathrm{CO}_{2}$ emissions by 2030 .

Specific vehicles will be assigned to GO!Durban routes, thereby serving different functions in comparison to the BAU scenario. Buses in the GO!Durban scenario are classified as articulate and standard buses based on capacity and route assignment, whereas only standard buses operate in the BAU scenario, resulting in intermediate reductions due to the extent of bus routes in GO!Durban. Even so, improvements in bus emissions comprise a consistent decline in emissions across all options. Further improvements with regard to the fuels used by buses might be investigated. For example, Vincent \& Jerram [29] showed that buses using compressed natural gas as fuel could make substantial savings in terms of GHG emissions. A variance in the distance driven by PT vehicles is directly proportional to emissions produced and will directly influence the results of this study. The results of this study are not sensitive to the energy consumption of the BAU fleet, however, a $10 \%$ change in the electricity consumption of rail (the most energy intensive PT mode) has a 6\%-8\% influence on the GHG emissions of the BAU Scenario.

\section{Phasing-in of G0!Durban and phasing-out of existing PT services}

The gradual phasing-in of the IRPTN and simultaneous phasingout of the existing minibus-taxis and bus routes is crucial for the success of the network. Concurrent systems will result in greater emissions and competitive services and will reduce patronage of GO!Durban. The case of unsynchronized phasing programmes (the event of trunk routes coming online without appropriate feeder and complementary routes, etc.) would result in altered emissions, which have not been included in this study. It must be considered that the introduction of a revolutionary network may have a rebound effect in reducing the number of minibus-taxis on the road and may in fact make POV usage appear more attractive. The leapfrog approach has been adopted by government for the shift towards GO!Durban. This phased approach of GO!Durban follows the introduction of Phase One (four corridors) and corresponding termination of existing PT services. Significant emission reductions will be achieved at the end of implementation of each corridor, and progress with each phase. Figure 6 provides an emission profile for the GO!Durban system and the BAU scenario according to the phased (leapfrog) approach (Figure 6).

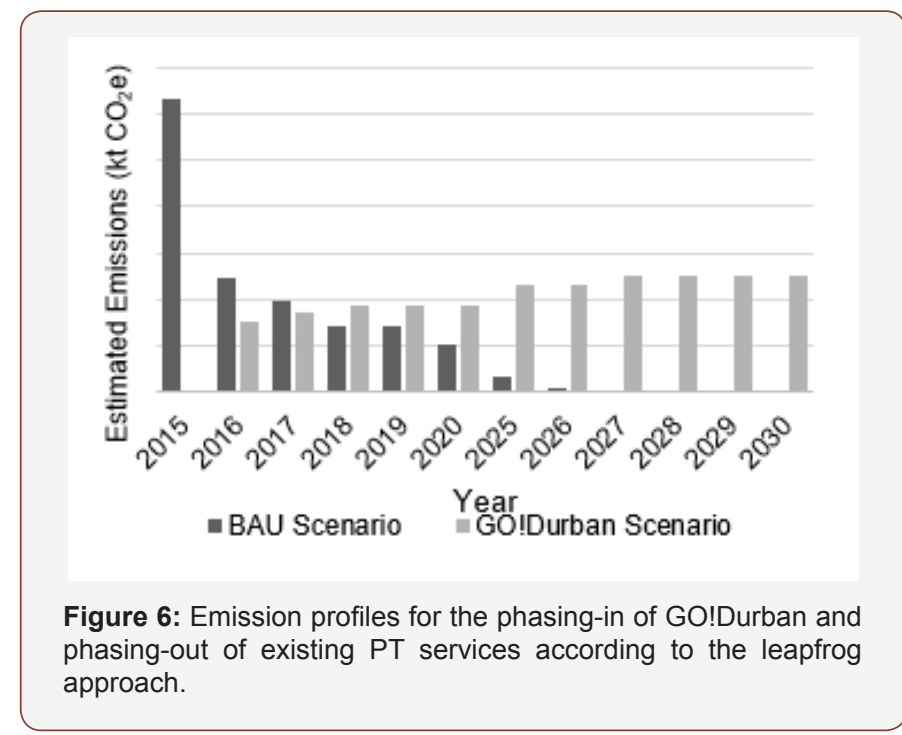

As anticipated, the operational emissions of the BAU scenario decrease with the termination of existing PT services and the emissions of GO!Durban increase to the completion of the network. The overall annual emissions of all PT services in the EMA are determined by the components of both systems, which exist at specific times during implementation. The cumulative emission reduction achieved during the period of implementation is dependent on the procedure followed. Figure 7 provides an overview of the total annual emissions produced by the PT according to the introduction of phases for the leapfrog approach (Figure 7). 


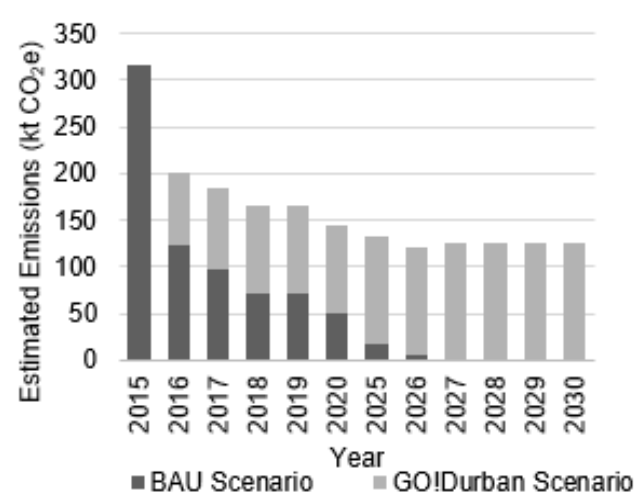

Figure 7: Overview of total emissions $\left(\mathrm{kt} \mathrm{CO}_{2} \mathrm{e}\right)$ of the PT sector during the shift to GO!Durban.

The overall emissions are shown to decrease rapidly with the implementation of GO!Durban phases to 2030. Although the approach adopted will not alter the emissions for the year of 2030, the procedure will determine the total emission reductions achieved over the implementation process. The environmental impact of an approach, similar to the development of the Rede Integrada de Transporte in Curitiba, which introduces steady improvements across all PT services in the EMA, must be considered. Incrementalism will produce small reductions in operational GHG emissions for various stages of advancement. Therefore, it is important to note that the annual reductions achieved at each level of improvement will accumulate during the shift to GO!Durban, and may exceed those reflected by leapfrogging, with a decreased environmental impact [30,31].

\section{Comparison with other local studies}

A quantitative comparison of the GHG emissions with the other two South African studies [23,24] was attempted, however, due to the different scopes of these studies, a full comparison was not possible. It can be seen though that the GHG emission reductions of GO!Durban (ex-ante) and Rea Vaya (monitored) display a similar trend of an achievable maxima of $60 \%$ and a $69 \%$ GHG savings, respectively. The Rea Vaya study, as modeled by Grütter [23], only considers a fraction of the PT services available in the City of Johannesburg. In contrast, GO!Durban is an extensive IRPTN spanning nine corridors across four phases. The similarity in results serve as an indication of the achievable success of GO!Durban. Although on a smaller scale, the transformation realised by Rea Vaya partially validates the results of this study and the potential of GO!Durban on a greater scale. When Bubeck et al. [24] quantified the potential GHG savings for the Rea Vaya and the Gautrain (mass rail transit scheme linking Johannesburg to Pretoria) using another methodology, the overall GHG savings were more modest and the mitigation cost relatively high (4948 to 30045 ZAR2013/t $\left.\mathrm{CO}_{2} \mathrm{e}\right)$ due to the infrastructure expansion. They highlighted that to achieve higher efficiency the IRPTNs implemented need to better integrate various public transportation modes and attract passengers away from using private cars. In their modelling, South
African minibus taxis proved to be efficient with regard to GHG emissions and, therefore, they recommended that these should be formalized and included as feeders. Hence, there is evidence that the IRPTNs planned for and partially implemented in South Africa can successfully contribute to reduce the GHG emissions of public transportation in the country, although as a GHG mitigation strategy it is relatively costly due to the infrastructure investment needed.

\section{Concluding Remarks and Recommendations}

The irreversible effects of climate change are increasing globally and cannot be ignored. Emission regulations must be applied world-wide and mitigative measures, together with adaptation to change, must be implemented. Although transportation is essential to the modern world, the impacts of the sector are rapidly increasing, pushing beyond $25 \%$ of global GHG emissions. However, the transport sector, in particular public transportation, creates the opportunity to reduce worldwide emissions on a large scale.

The inefficient PT services offered in the EMA have prompted the implementation of an IRPTN - GO!Durban, containing eight BRT and one rail trunk route, feeders and complementary services, and will introduce a formalized PT system for the provision of services in the municipality. This study, motivated by the shortage of carbon studies in the EMA and scenario analyses in particular, quantifies the current and projected GHG emissions of the PT sector by ex-ante GHG emission comparisons of the BAU Scenario and GO!Durban. The role of vehicles has clearly been defined in GO!Durban, by vehicle assignment to routes. As expected, these differ from the existing PT system and provide a transformational IRPTN in the eThekwini Municipality. The anticipated carbon footprint of vehicle operations of GO!Durban in 2030 are $177 \mathrm{kt} \mathrm{CO}_{2}$ e to 192 kt $\mathrm{CO}_{2}$ e for the latest Euro Emission Standard vehicle technologies. In comparison, the projected emissions of the BAU scenario are $384 \mathrm{kt} \mathrm{CO}_{2}$ e to $482 \mathrm{kt} \mathrm{CO}_{2} \mathrm{e}$. Even with increased ridership of the GO!Durban scenario (shift of $20 \%$ from POV to PT), the wall-to-wall network still emits less GHGs. Therefore, the expected operational emissions of GO!Durban in 2030 will be $54 \%$ to $60 \%$ lower than projected emissions of the existing PT system (BAU scenario), for the different vehicle technology options explored. The results of this ex-ante study are partially comparable to the carbon credits study conducted on the Rea Vaya BRT system in the City of Johannesburg, in which a $69 \%$ reduction in GHG emissions was monitored.

This indicates the achievable success of GO!Durban on a significantly larger scale, and the accomplishment of lower GHG emissions in the transport sector. This study is the first-of-its-kind for the GO!Durban system, upon which further studies can be built. More studies on other planned IRPTNs in SA are recommended as a measure of success in reducing the GHG emissions of the PT sector. Further studies investigating and evaluating various stages of implementation, including incrementalism and leapfrogging for the implementation of GO!Durban, in particular, are advisable. Different fuels for buses should be researched in the local context and should include compressed natural gas. The GHG emissions of each approach could assist in decisions for the most suitable way 
forward. Furthermore, the co-benefits of the GO!Durban system should be investigated, as less overall emissions are expected due to these co-benefits. In conclusion, the structure of GO!Durban has been determined according to travel demands of the public, therefore, the success of the system for GHG mitigation must be ensured (through various measures encouraging PT usage, including disincentives for POV usage). For the purpose of this study, the latest revision of the preliminary plans for GO!Durban were used, however, these may be adjusted and improved upon during implementation of the network. The major factor contributing to the operational emissions of the system is vehicle selection, therefore, this selection should be performed with respect to the latest available technology. The X'Trapolis Mega rail rolling stock with a regenerative braking system, is currently in manufacture for the GO!Durban system and latest European Emission Standard V buses are recommended for operation along bus routes. The quality of the current results can be improved in the future by increasing the accuracy of the EMME model used for the planned IRPTN. For example, planned developments like the future dig-out port expansion should be included.

\section{Acknowledgment}

None.

\section{Conflict of Interest}

No conflict of interest.

\section{References}

1. Sims R, Schaeffer R, Creutzig F, Cruz-Núñez X, D’agosto M, et al. (2014) Transport. In: Climate Change 2014: Mitigation of Climate Change. Contribution of Working Group III to the Fifth Assessment Report of the Intergovernmental Panel on Climate Change. Cambridge University Press, Cambridge, United Kingdom and New York, NY, USA.

2. CDM - Clean Development Mechanism (2011) Large-Scale Methodology, AM0031: Bus rapid transit projects, Version 05.0.0. Switzerland: United Nations Framework on Climate Change, Switzerland.

3. Delphi (2014) Worldwide Emission Standards Passenger Cars and Light Duty Vehicles [Online].

4. DoT RSA - Department of Transport Republic of South Africa (2007) Public Transport Action Plan [Online].

5. Scenario Building Team (2007) Long Term Mitigation Scenarios: Strategic Options for South Africa. Pretoria: Department of Environment Affairs and Tourism, South Africa.

6. Thambiran T, Diab R (2011) Air pollution and climate change co-benefit opportunities in the road transport sector in Durban, South Africa. Atmospheric Environment 45: 2683-2689.

7. Gibela Product Engineering (2014) Summary of the PRASA X'Trapolis Mega energy consumption, Internal Report, Gibela Rail Transport Consortium.

8. Zahabi S, Miranda-Morena L, Patterson Z, Barla P, Harding C (2012) Transportation Greenhouse Gas Emissions and its Relationship with Urban Form, Transit Accessibility and Emerging Green Technologies: A Montreal case study. Procedia - Social and Behavioural Sciences 54: 996-978.

9. Chen X, Wang Z (2012) Low-carbon scenario analysis on urban transport of one metropolitan in China in 2020. Journal of Industrial Engineering and Management 5(2): 344-353.
10. Walters J (2013) Overview of public transport policy developments in South Africa. Research in Transportation Economics, 39: 34-45.

11. Walters J (2014) Public transport policy implementation in South Africa: Quo vadis? Journal of Transport and Supply Chain Management 8 (1): 1-10.

12. Hitge G, Van Dijk ENR (2012) Incremental Approach to Public Transport System Improvements. Proceedings of the 31st Southern African Transport Conference, 9-12 July 2012. Pretoria, South Africa pp: 592603.

13. Siyongwana P, Binza M (2012) Challenges facing the transformation of the public transport system in Nelson Mandela Bay, South Africa: history in the making. Journal for Contemporary History 37: 191-202.

14. EM - eThekwini Municipality (2014a) Integrated Development Plan: Annual Report 2014/2015. Durban: eThekwini Municipality, South Africa.

15. EM - eThekwini Municipality (2014b) Spatial Development Framework (SDF) Report 2014/15 Review, South Africa.

16. EM - eThekwini Municipality (2015_GO!Durban moves ahead in 2015, South Africa.

17. INRO (2013) INRO Emme Products. INRO Software [Online].

18. Nair P, Kumar D (2005) Transformation in road transport system in Bogota: an overview. ICFAI Journal of Infrastructure, September pp: 2028.

19. Crozet Y, Lopez-Ruiz Hg (2013) Macromotives and microbehaviours: Climate change constraints and passenger mobility scenarios for France. Transport Policy 29: 294-302.

20. Cuenot F, Fulton L, Staub J (2012) The prospect for modal shifts in passenger transport worldwide and impacts on energy use and $\mathrm{CO} 2$. Energy Policy 41: 98-106

21. Wright, L. \& Hook, W. 2007. Bus Rapid Transit: Planning Guide 2007. New York: Institute for Transportation and Development Policy, South Africa.

22. Mejia-Dugand S, Hjelm O, Baas L, Rios R (2012) Lessons from the spread of Bus Rapid Transit in Latin America. Journal of Cleaner Production 50: 82-90.

23. Grütter J (2011) BRT Rea Vaya Phase 1a and 1b, South Africa, VCS Project Document, Version 1.2, Reinach.

24. Bubeck S, Tomascheck J, Fahl U (2014) Potential for mitigating greenhouse gases through expanding public transport services: A case study of Gauteng Province, South Africa, Transportation Research Part D 32: 57-69.

25. NH DoT - New Hampshire Department of Transport (2012) Remaining Useful Life of Transit Buses [Online]. New Hampshire Government,South Africa.

26. Chetty R (2013) Personal Communication. Senior Manager, eThekwini Transport Authority, South Africa.

27. PRASA - Passenger Rail Agency of South Africa. 2007. Metrorail - Rolling Stock [Online].

28. Eskom Holdings Limited (2011) The Eskom Factor Report. Johannesburg: Eskom Holdings Limited, South Africa.

29. Vincent W, Jerram L (2006) The potential for bus rapid transit to reduce transportation-related CO2 emissions, Journal of Public Transportation 9 (3): 219-237

30. Moodley GY, Chetty R, Reddy J, Simmer C (2011) Developing the Integrated Rapid Public Transport Network (IRPTN) for the eThekwini Municipal Area. Proceedings of the 30th Southern African Transport Conference, 11-14 July 2011, Pretoria, South Africa, pp. 499-514

31. TSA - Taxi Scrapping Administrator (2009) Progress Statistics, South Africa. 